\title{
NEW INSIGHTS INTO STUDYING AGENCY AND INFORMATION TECHNOLOGY
}

\author{
Tony Salvador \\ Intel Corporation \\ Jeremy Rose \\ University of Aalborg \\ Edgar A. Whitley \\ London School of Economics and Political Science \\ Melanie Wilson \\ Manchester School of Management
}

The question of how human action and information technology interact has been a recurrent theme in much information systems research, especially within the IFIP 8.2 community.

One of the key elements to understanding agency (Barnes 2000) is to question where the agency lies; a question that has both ontological and epistemological implications. Is the issue of agency one of human capabilities and human institutions? Is it a feature of technology or is it intimately implicated in the relationship between the two? In studying information systems, researchers have used many theoretical models to address this issue, with some of the most popular approaches being the application of critical theory (see, for example, Bloomfield and McLean 1996), structuration theory, and actor-network theory (see, for example, Latour 1996; Rose and Truex 2000).

This panel will present three proposals for how to study the question of agency and information technology and the audience will be asked to respond to each of the proposals, both in terms of their likely contributions to our understanding of information systems and their practical applicability.

In order to ground the various proposals, the panel will begin with a short presentation by Tony Salvador (panel chair) who will describe some recent research on retail environments. One of the findings of this research appeared to suggest that there 
was limited agency in these environments and that information and communications technologies played a role in reducing human agency.

He will then ask each of the other panelists to outline their approach to tackling the question of human agency and information technology, asking them to relate their view of how technology and agency interrelate to the case.

Melanie Wilson will draw on her previous research to argue that agency is a human attribute that is constrained and enabled by broader social factors. To that extent, information technology is only indirectly implicated in questions of agency through its role in supporting the dominant economic rationality of the day. Edgar Whitley, in contrast, will argue that questions of agency are a reflection of what we understand to be the capabilities of technology rather than humans. Questions of agency, then, depend on what the technology can't do, rather than what humans can do. Finally, Jeremy Rose will present the view that it is neither humans nor information technology in isolation that provide agency, but rather it is the imbroglios of the two that are "agentic" and that any attempts to isolate the two are artificial and hence likely to be problematic.

During the presentation audience members are encouraged to indicate their support or otherwise for each proposal. They are also encouraged to question the proposers about the likely contribution their proposal will make and the practical application of the approach proposed.

\section{REFERENCES}

Barnes, B. Understanding Agency: Social Theory and Responsible Action, London: Sage Publications, 2000.

Bloomfield, B. P., and McLean, C. "Madness and Organization: Informed Management and Empowerment," in W. J. Orlikowski, G. Walsham, M. R. Jones, and J. I. DeGross (Eds.), Information Technology and Changes in Organizational Work, London: Chapman \& Hall, 1996, pp. 371-396.

Latour, B. "Social Theory and the Study of Computerized Work Sites," in W. J. Orlikowski, G. Walsham, M. R. Jones, and J. I. DeGross (Eds.), Information Technology and Changes in Organizational Work, London: Chapman \& Hall, 1996, pp. 295-307.

Rose, J., and Truex III, D. "Machine Agency as Perceived Autonomy: An Action Perspective," in R. Baskerville, J. Stage, and J. I. DeGross (Eds.), Organizational and Social Perspectives on Information Technology, Boston: Kluwer Academic Publishers, 2000, pp. 371-390. 